\title{
Intraocular Colchicine Inhibits Competition Between Resident and Foreign Optic Axons for Functional Connections in the Doubly Innervated Goldfish Optic Tectum
}

\author{
BARBARA E. SCHLUMPF and ROGER E. DAVIS
}

Mental Health Research and Neuroscience Laboratory, University of Michigan, Ann Arbor, MI 48109 (U.S.A.)

(Accepted 1 April 1986)

Key words: Colchicine - Axonal transport - Axonal competition - Lumicolchicine - Classical conditioning Optic nerve regeneration - Optic tectum - Synaptogenesis - Goldfish

\begin{abstract}
After unilateral optic tectum ablation in the goldfish, regenerating optic axons grow into the optic layers of the remaining ipsilateral tectal lobe and regain visual function. The terminal arbors of the foreign fibers are initially diffusely distributed among the resident optic axons, but within two months the axon terminals from each retina are seen to segregate into irregular ocular dominance patches. Visual recovery is delayed until after segregation. This suggests that the foreign fibers compete with the residents for tectal targets and that the segregation of axon terminations is an anatomical characteristic of the process. Here we investigate whether inhibiting axonal transport in the resident fibers inhibits competition with foreign fibers. The eye contralateral to the intact tectal lobe received a single injection of $0.1 \mu \mathrm{g}$ colchicine, which does not block vision with the intact eye. We measured visual function using a classical conditioning technique. Segregation of axon terminations was examined shortly following visual recovery by autoradiography. The no-drug control fish showed reappearance of vision with the experimental eye at 9 weeks postoperatively and ocular dominance patches were well developed. Colchicine administered to the intact eye (resident fibers) several weeks postsurgery decreased the time to reappearance of vision with the experimental eye by several weeks. Autoradiography revealed some signs of axonal segregation but the labeled foreign axons were mainly continuously distributed. Administration of colchicine at the time of tectum ablation, or of lumicolchicine at two weeks postoperatively produced normal visual recovery times. Fast axonal transport of ${ }^{3} \mathrm{H}$-labeled protein was inhibited by 1.0 and $0.5 \mu \mathrm{g}$ but not by $0.1 \mu \mathrm{g}$ of colchicine or by $1.0 \mu \mathrm{g}$ of lumicolchicine. Previous studies showed that while $0.1 \mu \mathrm{g}$ of colchicine does not block vision it is sufficient to inhibit axonal regeneration following optic nerve crush. We conclude that two retinas can functionally innervate one tectum without forming conspicuous ocular dominance columns, and that the ability of residents to compete with the ingrowing foreign axons is very sensitive to inhibition of axoplasmic transport or other processes that are inhibited by intraocular colchicine.
\end{abstract}

\section{INTRODUCTION}

In goldfish, the majority of retinal ganglion cell axons cross the midline of the brain and terminate in the contralateral lobe of the optic tectum. When one tectal lobe is removed, severed optic fibers regenerate and recross the brain midline and terminate in the ipsilateral lobe ${ }^{33}$. Initially, the fibers from the two eyes are evenly distributed in the tectum and after 7-10 weeks they segregate into eye-specific bands ${ }^{18,19,36}$. The period of segregation corresponds to an increase in synapse formation ${ }^{2}$ and to the recovery of vision mediated by the regenerating foreign fibers ${ }^{8}$. Destroying the resident axons by removal of the opposite eye at the time of the tectal ablation facilitates re- covery of function in the foreign fibers. These findings suggest that the doubly innervated goldfish tectum provides a means of studying the mechanisms of interaxonal competition for targets ${ }^{3,8,22}$.

Factors which could affect the outcome of interaxonal competition include axon-target specificity 27 , synaptic geometry ${ }^{28}$, timing of arrival at the target ${ }^{32}$, transport of materials in the axon ${ }^{1,40}$ and visual stimulation $^{3.22}$. The present study was conducted to investigate the thesis that inhibition of axonal transport in the resident optic axons inhibits their ability to compete with ingrowing axons for functional synaptic sites on tectal neurons and, thereby, facilitates visual recovery in the foreign axons.

To inhibit axonal transport in the resident axons,

Correspondence: R.E. Davis, University of Michigan, Neuroscience Laboratory, 1103 E. Huron, Ann Arbor, MI 48109, U.S.A. 
the tubulin-binding drug, colchicine ${ }^{6.25}$ was injected into the eye contralateral to the remaining tectum. The dose used inhibits optic nerve regeneration following axotomy, possibly by inhibiting axonal transport, but does not block maintenance of visual function in the intact optic system ${ }^{10}$. We here examine for the first time the sensitivity of fast axoplasmic transport in the goldfish retinotectal projection to inhibition by intraocular colchicine and its comparatively inactive photoderivative, lumicolchicine ${ }^{25}$. Vision was assessed with an objective psychophysical technique which permits monocular and sequential testing in each fish ${ }^{7}$. The index of vision was a branchial suppression response (BSR) which was evoked by a conditioned stimulus (CS) consisting of a moving spot of red light. The CS was classically conditioned to an electric shock unconditioned stimulus (US). Segregation of axon terminations was assessed following visual recovery by autoradiography.

\section{MATERIALS AND METHODS}

\section{Fish and preoperative conditioning}

Goldfish (Carassius auratus L.), 8-10 g, obtained from Ozark Fisheries, Stoutland, MO, were kept in individual home tanks at $30^{\circ} \mathrm{C}$ as previously described $^{8}$; the water temperature was similar to that used by Springer and Cohen ${ }^{36}$.

Fish were conditioned individually as previously described $^{8.9}$. Branchial ventilation movements were detected by the thermistor method. The CS consisted of the flickering movement of a spot of red light produced by alternately illuminating two light-emitting diodes that were centered one above the other, $1 \mathrm{~cm}$ apart, approximately $2.5 \mathrm{~cm}$ from the eye. The US was a 0.5 -s pulse from 7 to $8 \mathrm{~mA}$ (RMS) $60 \mathrm{~Hz}$ constant current that was passed between two steel electrodes on opposite sides of the fish holder. Fish were screened to obtain individuals that responded to a 5-s presentation of the CS. The fish's BSR was measured using a digital conversion of the analog of the branchiogram trace during the 5-s CS-US interval (B) and during the 5-s interval (A) preceding the onset of the trial. The BSR was expressed as the percentage change in the length of the trace during interval $B$ relative to the length during $A, B S R=(100 \times[1-B / A])$. A deceleration of greater than $40 \%$ was accepted as a BSR indicative of visual detection of the $\mathrm{CS}^{7}$.
Fish that responded with each eye subsequently received the preoperative test session consisting of four 2-s warm-up trials followed by four 5 -s test trials. A blank trial, in which the CS and US were omitted. was administered prior to each test trial. Fish that responded in each of the 4 test trials and showed no false positives in blank trials were accepted as subjects. The preoperative test session was administered 2-7 days prior to the day of surgery.

\section{Surgery}

During surgery the fish were anesthetized in $0.04 \%$ trimethane methyl sulfonate (Sigma) buffered with Tris fish buffer (Sigma) to pH 6.5-7.5. To ablate the right lobe of the optic tectum (IOT fish), the tectal region was exposed by cutting a flap of bone in the roof of the cranium and the tissue was removed by aspiration. The bone flap was repositioned and, when necessary, held in place with Permabond superglue. Immediately following the tectum ablation, the right eye was removed in some fish. Fish were returned to their home tank to recover. The day of surgery was designated experimental Day 0.

\section{Experimental drugs}

Colchicine and $\beta$-lumicolchicine (Sigma) were administered intraocularly (i.o.) in the right eye (resident optic axons) using a 30-ga. needle and a $100-\mu 1$ Hamilton syringe ${ }^{10}$. Colchicine was delivered in water and lumicolchicine in PET-80 (ref. 9) or a mixture of DMSO (dimethylsulfoxide, Sigma) and MYRJ 52 detergent (Atlas Powder Co.). The volume of each i.o. injection was $5 \mu l$.

\section{Visual recovery time}

Fish screened for responding to the CS were randomly assigned to the various experimental groups. All the fish received unilateral right optic tectum ablation on Day 0. This was to induce optic axons from the left eye to invade the left tectum forming the ipsilateral optic tectum projection. Fish received no other experimental treatment (IOT, $n=13$ ), an i.o. injection of $0.1 \mu \mathrm{g}$ colchicine on Day $0(\mathrm{C}-0 \mathrm{~d}, \mathrm{n}=6)$ or Day $14(\mathrm{C}-14, \mathrm{n}=6)$ or Day $21(\mathrm{C}-21, \mathrm{n}=6)$ or 0.1 $\mu \mathrm{g}$ lumicolchicine on Day $14(\mathrm{~L}-14, \mathrm{n}=5)$. In 9 additional fish (X-0d), the right eye was removed on Day 0 to destroy the native or resident optic fibers of the left tectum. 
To measure the time to reappearance of vision with the left eye, as an index of the time to formation of functional synapses between the regenerating foreign optic axons and targets in the left tectum, the fish were tested for response to the CS in weekly sessions beginning one week following surgery. The procedure in postoperative sessions was the same as in the preoperative test session. Visual recovery was inferred when the fish responded (BSR $>40 \%$ ) in left-eye trials in two successive, weekly sessions and the day of the first session was taken as the day of recovery.

The data for each session were reduced by computing the mean BSR in left eye trials for each fish. The time to reappearance of vision for individuals was estimated as the day on which the mean BSR reached $50 \%$. The time to $50 \%$ recovery was derived from the regression of the mean BSR against the postoperative day. Mean $50 \%$ times for the groups were contrasted using a one-way ANOVA and the Duncan Range-test.

\section{Distribution of optic axons in the tectum}

Following behavioral testing, the retinotectal projections were traced by autoradiography ${ }^{35}$. Immediately after the second weekly test session in which the fish showed left-eye vision, the left eye received an injection of $30 \mu \mathrm{Ci}$ of $\left[{ }^{3} \mathrm{H}\right]$ proline $(20-40 \mathrm{Ci} / \mathrm{mmol}$, Amersham). Thus, the foreign retinotectal projection was labeled one week after the session in which visual function reappeared. They were killed $24 \mathrm{~h}$ later by immersion in the anesthetic. Their heads were fixed in alcohol-formalin-acetic acid, and embedded in paraffin to obtain $15 \mu \mathrm{M}$ thick transverse sections of the midbrain. The 4 groups that were examined were the normal IOT fish, the $\mathrm{X}-0 \mathrm{~d}$ and $\mathrm{C}-14 \mathrm{~d}$ fish. Four intact, experimentally naive fish were also examined. The data for C-0d, C-21d and L-14d fish were lost during the autoradiography procedure.

Slides were coded so that examination of the distribution of labeled optic fibers in the stratum fibrosum et griseum superficiale (SFGS) of the tectum was done without knowledge of the experimental treatment. Two sections were chosen randomly from the rostral, middle and caudal thirds of each tectum. Bands of high density labeling indicative of ocular dominance patches were easily seen with darkfield illumination (e.g. Fig. 4, IOT brain). We adapted the method of Springer and Cohen ${ }^{36}$ to express the proportion of the dorsal to ventral extent of SFGS that contained patches of heavy label. We similarly measured the percent of area of SFGS that was labeled only lightly and the area that was labeled at background level and thus appeared to contain no labeled fibers. The mean percent data for the various groups and were contrasted using a one-way ANOVA and the Duncan Range-test.

\section{Axonal transport of ${ }^{3} \mathrm{H}$-labeled protein}

To examine whether the i.o. colchicine inhibited axonal transport in the resident retinotectal projection, unconditioned fish were administered $0.1 \mu \mathrm{g}$ $(\mathrm{n}=7), 0.5 \mu \mathrm{g}(\mathrm{n}=8)$ or $1.0 \mu \mathrm{g}(\mathrm{n}=8)$ colchicine 3 days prior to measuring axonal transport. Additional unconditioned fish were similarly administered $\gamma$-lumicolchicine $(n=3)$, water $(n=3)$ or DMSO-MYRJ $(n=4)$.

Axoplasmic transport in the retinotectal projection was assessed by measuring radioactivity in protein in each tectum lobe $24 \mathrm{~h}$ following administration of $3 \mu \mathrm{Ci}\left[{ }^{3} \mathrm{H}\right]$ proline $(20-40 \mathrm{Ci} / \mathrm{mmol}$, Amersham) in the right eye $\mathrm{e}^{14}$. The $\mathrm{dpm} / \mathrm{mg}$ protein for the left tectum lobe was indexed to that for the right lobe to control for the amount of uptake of systemic $\left[{ }^{3} \mathrm{H}\right]$ proline

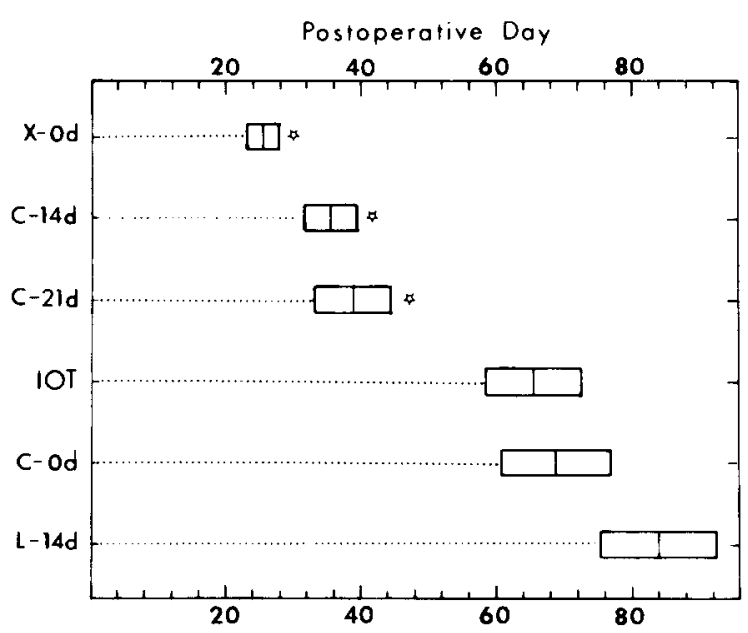

Fig. 1. The effects of i.o. administration of colchicine, lumicolchicine, or of surgical destruction of resident optic axons from the right eye on the time to recovery of visual function in foreign axons from the left eye. The mean time to $50 \%$ recovery of vision (BSR $=50 \%$ ) and the S.E.M.s are plotted for normal IOT fish, in which the resident axons were untreated, others in which the right eye was removed $(X)$ on Day 0 , and others which received colchicine (C) on Day 0,14 or 21 , or lumicolchicine on Day 14. 
into tectal protein. The tectum was removed, frozen over dry ice and kept at $-20^{\circ} \mathrm{C}$ until radioactivity and protein measurements were made. Each lobe was homogenized ice cold in $0.1 \mathrm{ml}$ water. Trichloroacetic acid precipitable radioactivity was measured by a filter paper method ${ }^{21}$. Protein concentration was measured by spectrophotometry ${ }^{20}$. During the 24 -h period of protein labeling and transport, the fish were kept in separate tanks at $25^{\circ} \mathrm{C}$.

\section{RESULTS}

\section{Visual recovery and axonal segregation}

The mean times to $50 \%$ recovery of vision with the left eye are presented in Fig. 1. Recovery time was decreased $(P<0.01)$ when colchicine was administered in the right eye 14 or 21 days postsurgery. Right eye enucleation resulted in a slightly larger decrease in recovery time $(P>0.05$, contrasted to Day 14 colchicine group). Recovery of left eye vision was not

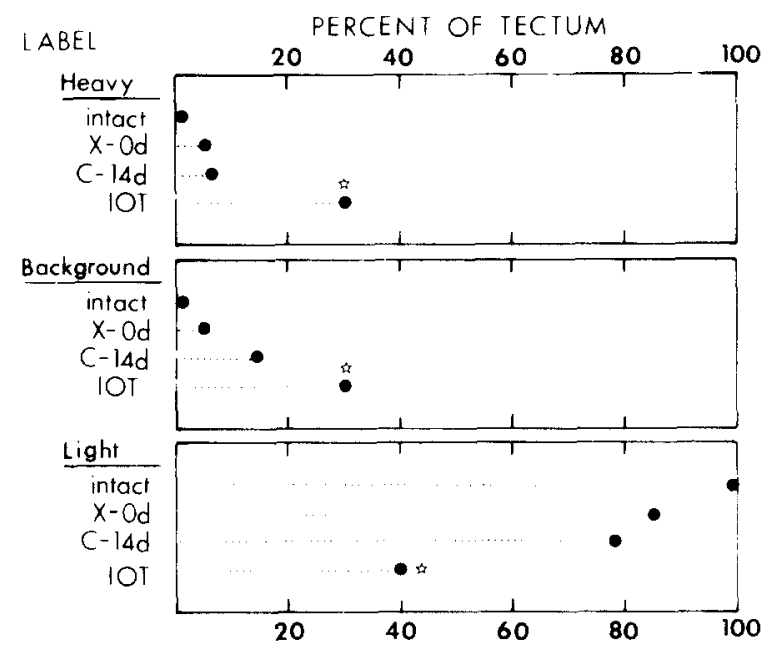

Fig. 2. Effects of colchicine intoxication or surgical destruction of resident optic axons from the right eye on the distribution of foreign optic axons from the left eye in the left optic tectum. Axons were labeled by administering $\left[{ }^{3} \mathrm{H}\right.$ ]proline in the left eye. The data show the distribution of labeled axons in the SFGS as seen in autoradiographs of transverse sections of the brain (Fig. 3). The mean percent of the dorsal to ventral extent of SFGS that was labeled either heavily, lightly or only at background level is plotted for normal IOT fish, in which the residents were untreated, and IOT fish which received righteye removal (X) on Day 0 or i.o. colchicine (C) on Day 14 following tectum surgery. The data for the intact control fish, which received no experimental treatment, show the distribution of resident optic axons from the left eye in the right tectum. The bars show the S.E.M. significantly affected by colchicine injected on Day 0 or by lumicolchicine injected on Day $14(P>0.05$. contrasted to IOT fish). Left eye vision reappeared in every fish. The ANOVA revealed a significant Groups effect $\left(F_{5,26}=12.87, P<0.01\right)$. Right eye vision was maintained in every fish, indicating that the colchicine did not block visual function in the resident retinotectal projection.

The pattern of labeling of the tectum in the autoradiograms differed between the groups (Figs. 2, 3). Every IOT fish showed distinct ocular dominance patches; of the 78 sections of tectum examined, 68 showed segregation of foreign axons (Fig. 4). The IOT fish had more heavy label area in SFGS $\left(F_{3,28}=\right.$ $16.48, P<0.01)$ than the intact fish, the $C-14 \mathrm{~d}$ and the $\mathrm{X}-0 \mathrm{~d}$ fish, and showed a complimentary increase in background label area $\left(F_{3,28}=7.94, P<0.01\right)$, which presumably contained mainly unlabeled resident optic axons, and decreased light label area. In contrast, SFGS was uniformly lightly labeled in the intact fish. The label density appeared to vary between sections from different fish and different zones of the tectum, but there were no distinct gaps or patches suggesting ocular dominance patches. Small patches of heavy label and of background label were seen in 13 out of the 36 sections of C-14d fish tectum and 7 of the 54 sections of X-0d fish tectum.

\section{Axonal transport}

Colchicine inhibited axonal transport from the ${ }^{3} \mathrm{H}$ labeled right retina to the left optic tectum, and the

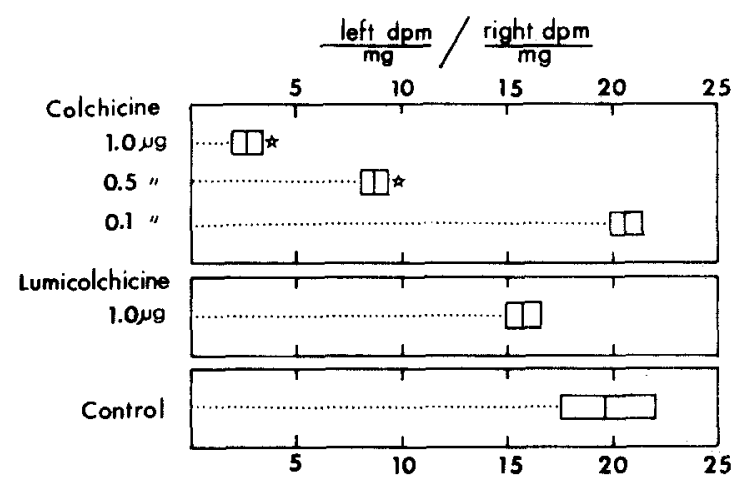

Fig. 3. The effects of i.o. colchicine or lumicolchicine on axonal transport of ${ }^{3} \mathrm{H}$-labeled protein from the left eye to the right optic tectum during a $24-\mathrm{h}$ period beginning 3 days after the drug was administered. The mean left/right tectum ratio was decreased by colchicine but not by lumicolchicine. The bars show the S.E.M. 


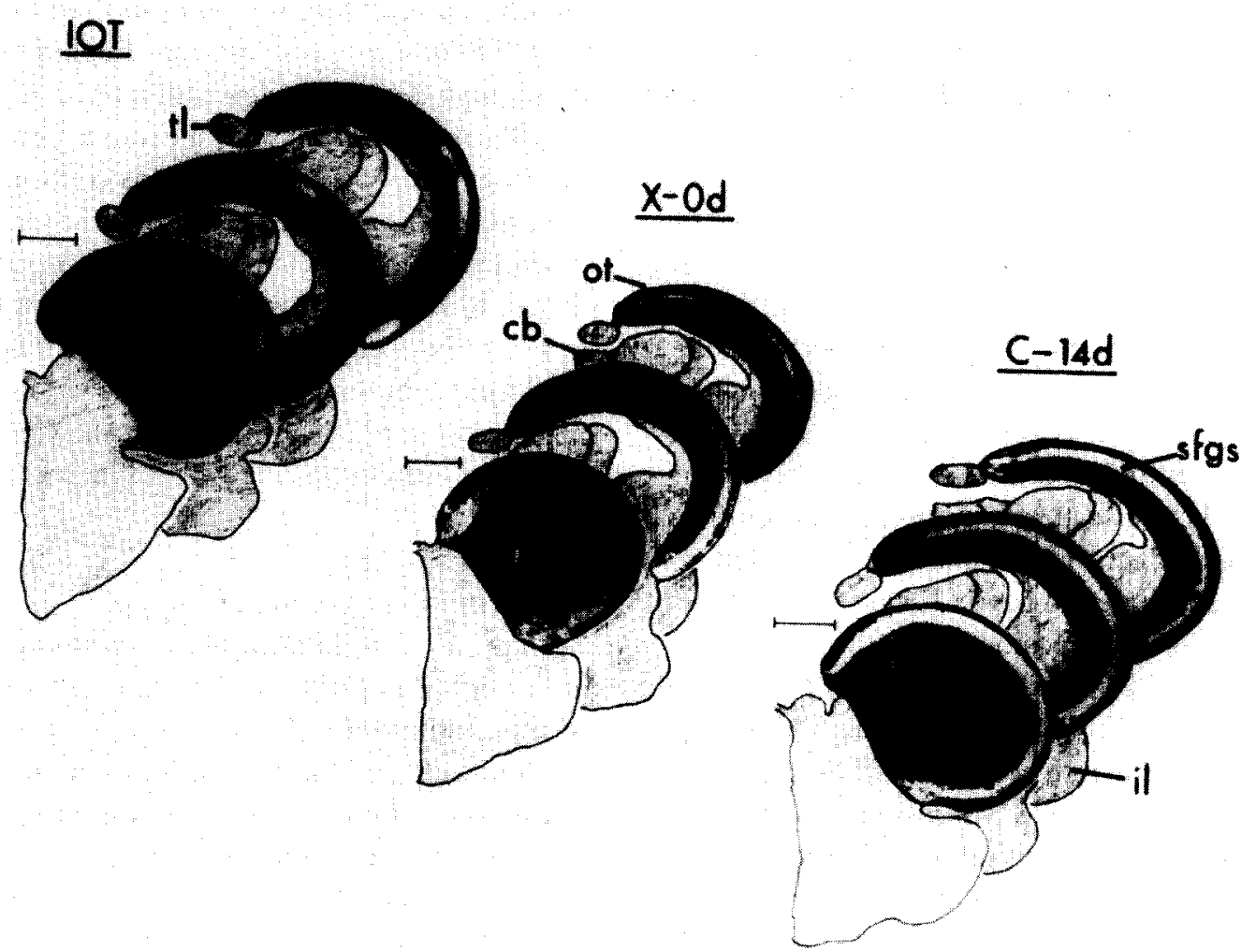

Fig. 4. Effect of i.o. colchicine intoxication or surgical destruction of resident optic axons from the left eye on the distribution of foreign axon terminations in the left optic tectum. The fish received $\left[{ }^{3} \mathrm{H}\right]$ proline in the left eye to label the foreign fibers. Shown are darkfield photomicrographs of representative, transverse sections of optic tectum from a normal IOT fish, in which the resident axons were untreated, and IOT fish which received right-eye removal (X) on Day 0 or i.o. colchicine (C) on Day 14 following tectum surgery. The 3 sections are, in ascending order, from the rostral, central and caudal thirds of the tectum. Abbreviations: cb, cerebellum; il, inferior lobe of the hypothalamus; ot, optic tectum; SFGS, stratum fibrosum et griseum superficiale; tl, torus longitudinalis.

inhibition increased with the dose up to $1.0 \mu \mathrm{g}$ (Fig. 3). The fish receiving water or DMSO-MYRJ showed similar ratios of protein-specific radioactivity in the left as opposed to the right optic tectum and the data were combined, as the control group. Group differences were evaluated with an ANOVA and the Duncan Range-Test. The analysis revealed a significant Groups effect $\left(F_{4,28}=25.01, P<0.01\right)$. Contrasting each drug group to the controls showed no effect for $0.1 \mu \mathrm{g}$ colchicine $(P>0.05)$ or $1.0 \mu \mathrm{g}$ lumicolchicine $(P>0.05)$ (Fig. 3).

\section{DISCUSSION}

\section{Colchicine effects on axonal competition}

These results imply that the ability of the resident optic axons in an intact lobe of the optic tectum to compete against regenerating foreign optic axons for targets is inhibited by acute colchicine intoxication. The mean time to reappearance of vision with the experimental eye was decreased from the 9 weeks shown by IOT fish (Fig. 1) to ca. 5 weeks. We infer from previous brain lesion studies, which showed that response to the CS is blocked after removal of the remaining tectum, that the restored visual function was mediated by the retinotectal projection ${ }^{8}$. Additional experiments are needed to establish whether colchicine inhibits axonal segregation. Every C-14d fish showed limited patches of heavy label in SFGS, as though foreign axons were segregating (Fig. 2), and the patches occurred in sections from various zones of the tectum in different fish. The foreign axons were labeled ca. 5-7 weeks after unilateral tectum ablation, which coincides with the early stages of axonal segregation ${ }^{2,36}$. Thus, the pattern seen in the C-14d brains might reflect normal, incipi- 
ent segregation. However, these preliminary data are unclear because signs of axonal segregation occasionally occur in X-Od fish (Fig. 2; see also Lo and Levine $^{19}$ ) in which the resident axons have been removed. Studies are needed of the effects of colchicine on segregation 7-12 weeks after the tectum ablation when ocular dominance patches normally reach full development. The present results tell us only that two retinas can innervate one tectum without forming conspicuous ocular dominance columns.

Colchicine's action is apparently reversed in $2-4$ weeks. We administered it several weeks following removal of the left tectum to intoxicate the resident optic axons during the period in which the foreign axons could be assumed to have reached the right tectum, that is $3-4$ weeks postoperatively ${ }^{36}$. Our behavioral data for $\mathrm{X}-0 \mathrm{~d}$ fish, which are among the first to regain vision (Fig. 1; see also Davis and Schlumpf ${ }^{8}$ ), confirm that regenerating foreign axons reach the left tectum within 3 weeks. This assumes that removal of the right (intact) eye and, thereby, destruction of the resident axons, acts mainly to facilitate target acquisition by the foreign axons and not their rate of growth in reaching the left tectum. Since the drug was also effective when given two weeks, but not immediately, following the tectal ablation, the duration of its inhibitory effect on competition is inferred to be more than one and less than three weeks.

Another conclusion is that interaxonal competition is highly sensitive to i.o. colchicine. The decrease in visual recovery time in the foreign axons was equivalent to that obtained when the resident axons are axotomized by removing the right eye (X-0d; Fig. 1). The mean time to $50 \%$ recovery ( 25 days) in the axotomy fish may be limited by the minimum time required for the arrival of the regenerating axons in the right tectum. Increasing the dose of colchicine administered at 3 weeks postoperatively, to more severely impair the resident fibers, might thus not produce a further decrease in visual recovery time in the foreign fibers. But doses below $0.1 \mu \mathrm{g}$ would presumably result in increased recovery times ranging up to 65 days, that is, the mean recovery time in IOT fish which receive no drug (Fig. 1).

The $0.1-\mu \mathrm{g}$ dose of colchicine was chosen as one which previous experiments had showed could be inferred to inhibit axonal transport in the retinotectal projection without blocking visual function ${ }^{10}$. Those studies showed that i.o. administration of $0.01 \mu \mathrm{g} / \mathrm{g}$ bw (0.08-0.11 $\mu$ g per eye) at the time of optic nerve crush inhibits axonal regeneration but does not block maintenance of response to the moving spot CS with an intact eye. The latter finding is confirmed by the present experiments. The earlier studies showed that intact eye vision was impaired within 3 and restored within 10 days following i.o. injection of $0.05 \mu \mathrm{g} / \mathrm{g}$ b.wt. (0.4-0.55 $\mu \mathrm{g}$ per eye) and that $1.0 \mu \mathrm{g}$ of lumicolchicine does not impair intact eye vision or axonal regeneration. Studies in progress show that $1.0 \mu \mathrm{g}$ colchicine blocks intact eye vision for at least 4 weeks.

\section{Colchicine effects on axonal transport}

That $1.0 \mu \mathrm{g}$ of lumicolchicine was non-toxic suggests that the inhibitory effects of $0.1 \mu \mathrm{g}$ of colchicine on the maintenance of vision and the recovery of vision following optic nerve crush or unilateral tectum ablation, are linked to its effects on microtubules or axonal transport. Lumicolchicine is a derivative of colchicine which binds to various axoplasmic proteins, membranes and organelles, but differs from colchicine in being a very weak inhibitor of microtubules or axonal transport ${ }^{6,25}$.

The biochemical data in Fig. 3 show that axonal transport from the retina to the tectum is inhibited by i.o. colchicine but not by the $0.1 \mu \mathrm{g}$ dose. This could indicate that the drug inhibits axonal regeneration and competition by some other mode of action or that the effect on transport is undetectable by the biochemical method. We administered the labeled proline 3 days following colchicine, in part because the time course of inhibition of intact eye vision produced by $0.5 \mu \mathrm{g}$ colchicine peaks at $3-5$ days ${ }^{10}$ and a similar time course of inhibition of axonal transport was obtained with i.o. colchicine in pigeon optic nerve ${ }^{26}$.

There are few dose-response studies of the effects of tubulin-binding drugs on axonal transport and visual function in optic nerve fibers. Fast axonal transport in rainbow trout optic nerve is inhibited by i.o. administration of $10 \mu \mathrm{g}$ but not $5 \mu \mathrm{g}$ of colchicine ${ }^{31}$. In pigeons, i.o. colchicine $(10-100 \mu \mathrm{g})$ produces reversible changes in the structure of optic axon terminals, inhibition of axonal transport and electrically stimulated synaptic transmission in optic axons ${ }^{5,26}$. Fast axonal transport in rabbit optic nerve is inhibited by 25 
$\mu \mathrm{g}$ of i.o. colchicine, whereas a similar dose of lumicolchicine is ineffective. Investigation of the effects of varying doses of colchicine on the profile of retinal proteins that are transported to the optic tectum ${ }^{14}$ may reveal changes related to the inhibition of axonal regeneration and competition.

\section{Axonal segregation and functional synaptogenesis by foreign axons}

Segregation of retinal projections, as obtained in goldfish by removing one tectum ${ }^{18}$ and in clawed frogs by the tectum ablation method, or by implanting a third eye or creating a 2-half-retina compound eye in the embryo ${ }^{13,16}$ resembles the ocular dominance areas or patches which appear in normal mammalian visual cortex and tectum ${ }^{15,17,29}$. The fish retina normally projects principally to the contralateral tectum; projection to the ipsilateral tectum occurs in some rayfinned fishes. Few fibers are involved and whether they form ocular dominance patches is unknown. Ipsilateral retinotectal fibers occur in goldfish $^{37}$, the black piranha ${ }^{12}$, and non-teleost rayfinned fishes such as gars and the bowfin ${ }^{24}$. Northcutt ${ }^{23}$ noted that ipsilateral retinotectal projection in the Australian lungfish is sparse and distributed in 'puffs', rather than continuously, in the tectum. Additional studies of ipsilateral retinotectal projections in fishes are needed to determine whether the rule of segregation of bilateral retinotectal projections applies.

Segregation of visual cortical projections in mammals can be inhibited by decreasing visual input by dark-rearing or by chronic, bilateral administration of tetrodotoxin (TTX) ${ }^{38,39}$. Chronic, bilateral, TTX blockade of visual input activity also inhibits segregation of the foreign and resident optic axons in goldfish tectum $^{3,22}$. Shortly after the TTX treatment period, postsynaptic field potentials can be evoked by electrical stimulation of the optic nerve. This suggests that the foreign axons had formed synapses during the period of blockade of activity ${ }^{3}$. Whether the chronic TTX-treatment results in decreased time to synaptogenesis in the foreign axons was not reported.

In normal IOT fish, segregation appears to be necessary for visual recovery in the foreign axons ${ }^{8}$. How much segregation needs to occur to enable visual recovery is a matter for future study. Regenerating foreign axons are distributed retinotopically in the remaining tectum ${ }^{11,33}$ at least several weeks prior to conspicuous axonal segregation ${ }^{36}$, to appearance of new synapses ${ }^{2}$, and to functional innervation of tectal targets ${ }^{8}$. Thus, while the opposite has been implicitly suggested, electrophysiological mapping of presynaptic potentials or mapping axon terminations in the tectum by light-microscopy may be misleading indicators of whether regenerating fibers have formed functional connections with targets.

\section{How might colchicine inhibit axonal competition}

When the resident axons are intoxicated by colchicine, it is as though they are absent or offer no significant impediment to synaptogenesis in the ingrowing foreign axons. Blockade of axonal transport might facilitate, that is, disinhibit, synapse formation in foreign fibers by depleting trophic and/or antitrophic substance which maintains the resident axon arbors. Retrograde transport of trophic substance from target cells may be necessary to maintain synapses ${ }^{34}$. Colchicine-effects on interaxonal competition have previously been reported. Experiments in the peripheral nervous system of salamanders show that colchicine-intoxication of intact nerve fibers results in sprouting of nearby intact fibers which subsequently innervate the denervated area, possibly by blocking transport of antitrophic factors ${ }^{1,4}$. Our behavioral data indicate that the i.o. colchicine acts through processes other than inhibiting visual activity in the resident retinotectal circuits. Colchicine-induced damage in optic axon terminals ${ }^{5}$ may weaken synapses or decrease the terminal arbor, thereby increasing the availability of synaptic sites to be captured by the foreign axons without blocking activity to the extent that the CS no longer evokes the BSR. The possibility that only a small portion of the resident projection needs to be functional and that the foreign axons synapse in zones where the residents are inactive needs investigation. Colchicine might also result in depletion of some axonally transported protein fraction, membrane or organelle which is necessary for encoding axons from each eye and possibly retinal position ${ }^{13}$. This might temporarily mask or alter the identity of the resident axons, leaving the foreign axons uninhibited in forming new functional synapses with tectal cells. 


\section{REFERENCES}

1 Aguilar, C.E., Bisby, M.A., Cooper, E. and Diamond, J.. Evidence that axoplasmic transport of trophic factors is involved in the regulation of peripheral nerve fields in salamanders, J. Physiol. (London), 234 (1973) 449-464.

2 Airhart, M.J.and Norden, J.J., Retinotectal synapses formed by ipsilaterally projecting fibers in the doubly innervated goldfish tectum, Brain Research, 324 (1985) $307-312$.

3 Boss, V.C. and Schmidt, J.T., Activity and the formation of ocular dominance patches in dually innervated tectum of goldfish, J. Neurosci., 12 (1984) 2891-2905.

4 Cooper, E., Diamond, J. and Turner, C., The effects of nerve section and of colchicine treatment on the density of mechanosensory nerve endings in salamander skin, $J$. Physiol. (London), 264 (1977) 725-749.

5 Cuenod, M.. Sandri, C. and Akert, K., Enlarged synaptic vesicles in optic nerve terminals induced by intraocular injection of colchicine, Brain Research, 39 (1972) 285-296.

6 Dahlström, A., Heiwall, P.O. and Larsson, P.A., Comparison between the effect of colchicine and lumicolchicine on axonal transport in rat motor neurons, J. Neurol. Trans., 37 (1975) 305-311.

7 Davis, R.E. and Schlumpf, B.E., Circumvention of extraretinal photoresponses in assessing the recovery of vision in goldfish following optic nerve crush, Behav. Brain Res., 7 (1983) 65-79.

8 Davis, R.E. and Schlumpf, B.E., Visual recovery in goldfish following unilateral optic tectum ablation: evidence of competition between optic axons for tectal targets, Behav. Brain Res., 13 (1984) 287-291.

9 Davis, R.E., Schlumpf, B.E. and Klinger, P.D., Systemic colchicine inhibits goldfish optic nerve regeneration, Toxicol. Appl. Pharmacol., 73 (1984) 268-274.

10 Davis, R.E., Schlumpf, B.E. and Klinger, P.D., Comparative neurotoxicity of tubulin binding drugs: inhibition of goldfish optic nerve regeneration, Toxicol. Appl. Pharmacol., 80 (1985) 308-315.

11 Easter, S.S. and Schmidt, J.T., Reversed visuomotor behavior mediated by induced ipsilateral retinal projections in goldfish, J. Neurophysiol., 40 (1977) 1245-1254.

12 Ebbesson, S.O.E. and Ito, H., Bilateral retinal projection in the black piranha (Senasalmus niger), Cell Tissue Res., 213 (1980) 483-495.

13 Fawcett, J.W. and Willshaw, D.J., Compound eyes project stripes on the optic tectum in Xenopus, Nature (London), 296 (1982) 350-352.

14 Heacock, A.M. and Agranoff, B.W., Protein synthesis and transport in the regenerating goldfish visual system, Neurochem. Res. 7 (1982) 771-788.

15 Hubel, D.H., Wiesel, T.N. and LeVay, S., Plasticity of ocular dominance columns in monkey striate cortex, Philos. Trans. R. Soc. London, 278 (1977) 377-409.

16 Law, M. and Constantine-Paton, M., Right and left eye bands in frogs with unilateral tectal ablations, Proc. Natl. Acad. Sci. U.S.A., 77 (1980) 2314-2318.

17 LeVay, S., Hubel, D.H. and Wiesel, T.N., The development of ocular dominance columns in normal and visually deprived monkeys, J. Comp. Neurol, 191 (1980) 1-51.

18 Levine, R.L. and Jacobson, M., Discontinuous mapping of retina onto tectum innervated by both eyes, Brain Research, 98 (1975) 172-176.

19 Lo, R.Y.S. and Levine, R.L., Time course and pattern of optic fiber regeneration following tectal lobe removal in the goldfish, J. Comp. Neurol., 191 (1980) 295-314.
20 Lowry, O.H., Rosebrough, N.J., Farr, A.L. and Randall. R.J., Protein measurement with Folin phenot reagent, I Biol. Chem., 193 (1951) 265-275.

21 Mans, P.J. and Novelli. G.D., Measurement of the incorporation of radioactive amino acids into protein by a filter paper method, Arch. Biochem., 94 (1961) 48-53.

22 Meyer, R.L.. Tetrodotoxin blocks the formation of ocular dominance columns in goldfish. Science, 218 (1982) $589-591$.

23 Northcutt, R.G., Retinal projections in the Australian lungfish, Brain Research, 185 (1980) 85-90.

24 Northcutt, R.G., Evolution of the optic tectum in rayfinned fishes. In R.E. Davis and R.G. Northcutt (Eds.), Fish Neurobiology, Vol. 2, University of Michigan Press. Ann Arbor, 1983, pp. 1-42.

25 Paulson, J.C. and McClure, W.O., Inhibition of axoplasmic transport by colchicine, podophyllotoxin, and vinblastine: an effect on microtubules, Ann. N.Y. Acad. Sci., 253 (1975) 517-527

26 Perisic, M. and Cuenod, M., Synaptic transmission depressed by colchicine blockade of axoplasmic flow. Science, 175 (1972) 1140-1142.

26a Price, M.T., The effects of colchicine and lumicolchicine on the rapid phase of axonal transport in the rabbit visual system, Brain Research, 77 (1974) 497-501.

27 Purves, O., Competitive and non-competitive re-innervation of mammalian sympathetic neurones by native and foreign fibers, J. Physiol. (London), 261 (1976) 453-475.

28 Purves, $O$., Modulation of neuronal competition by postsynaptic geometry in autonomic ganglia, TINS, 6 (1983) $10-16$.

29 Rakic, P., Prenatal genesis of connections subserving ocular dominance in the rhesus monkey, Nature (London), 261 (1976) $467-471$

30 Omitted.

31 Schönhartung, M., Breer, H., Rahmann, H., Gunter, S. and Raener, $\mathrm{H}$., Colchicine, a novel inhibitor of fast axonal transport without tubulin binding properties, Cytobiologie, 16 (1977) 106-117.

32 Scott, S.A., MacIntyre, T. and Diamond, J., Competitive re-innervation of salamander skin by regenerating and intact mechanosensory nerves, Proc. Roy. Soc. London, Ser. B., 211 (1981) 501-511.

33 Sharma, S.C., Anomalous retinal projection after removal of contralateral optic tectum in adult goldfish, Exp. Neurol., 41 (1973) 661-669.

34 Sperry, R.W., Chemoaffinity in the orderly growth of nerve fiber patterns and connections, Proc. Nat. Acad. Sci. U.S.A., 50 (1963) 703-710.

35 Springer, A.D. and Agranoff, B.W., Effect of temperature on rate of goldfish optic nerve regeneration: autoradiographic and behavioral study, Brain Research, 128 (1977) $405-415$.

36 Springer, A.D. and Cohen, S.M., Optic fiber segregation in goldfish with two eyes innervating one tectal lobe, Brain Research, 225 (1981) 23-26.

37 Springer, A.D. and Gaffney, J.S., Retinal projections in the goldfish: a study using cobatous-lysine, J. Comp. Neurol., 203 (1981) 401-424.

38 Stryker, M.P., Late segregation of geniculate afferents to the cat's visual cortex after recovery from binocular impulse blockade, Soc. Neurosci. Abstr., 7 (1981) 842.

39 Swindale, N.V., Absence of ocular dominance patches in dark-reared cats, Nature (London), 290 (1981) 332-333.

40 Weiss, P., Nervous system (neurogenesis). In B.H. Willier, $P$. Weiss and $r$. Hamburger (Eds.), The Analysis of Development, Saunders. Philadelphia. 1955, pp. 346-401. 